\title{
Effects of 8 week resistance training on lipid profile and insulin levels in overweight/obese peri-pubertal boys- a pilot study
}

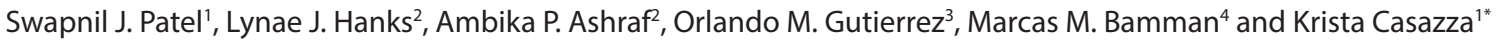 \\ *Correspondence: kcasazza@peds.uab.edu

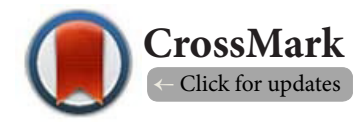 \\ 'Department of Pediatrics, Division of General Pediatric and Adolescent Medicine, School of Medicine, University of Alabama at \\ Birmingham (UAB), Birmingham, USA. \\ ${ }^{2}$ Department of Pediatrics, Division of Pediatric Endocrinology, School of Medicine, University of Alabama at Birmingham (UAB), \\ Birmingham, USA. \\ ${ }^{3}$ Division of Nephrology, School of Medicine, University of Alabama at Birmingham (UAB), Birmingham, USA. \\ ${ }^{4}$ Department of Cell, Developmental and Integrative Biology, University of Alabama at Birmingham (UAB), Birmingham, USA.
}

\begin{abstract}
Background: Approximately 30\% of overweight/obese children display an adverse lipid profile. While weight loss is the commonly prescribed intervention, success in treatment has been limited. The substantial involvement of lipid metabolism by skeletal muscle suggests resistance training has the potential to improve lipid profile even in the absence of weight loss, although investigations in the pediatric population are limited. The objective of this study was to investigate the effect of an 8-week resistance training program on lipid profile in overweight/obese peri-pubertal boys.
\end{abstract}

Methods: 8 overweight/obese, peri-pubertal boys (ages 10-12) were randomized to either a control $(\mathrm{n}=3)$ or resistance training $(\mathrm{n}=5)$ group. The resistance training protocol included 7 exercises consisting of 3 sets with 10-15 repetitions to fatigue 3 days per week for 8 -weeks. Fasting blood draw, strength testing and DXA were performed at baseline and 8-weeks for evaluation of lipid profile, strength, and body composition, respectively.

Results: Following the intervention, a marginal decrease in LDL $(p=0.08)$ and increase in TG $(p=0.07)$ in the resistance trained group were observed while no changes were apparent in controls. There were significant improvements in lower body strength in the resistance-trained group, while there were significant improvements in upper body strength in the control group. Weight increased in RT whereas did not in control.

Conclusion: In this pilot study, an 8-week resistance training program did not improvelipid profilein obese/ overweight peri-pubertal boys. However, the findings suggest a larger study with greater duration warrants consideration.

Keywords: Puberty, lipids, insulin, growth, resistance training

\section{Introduction}

The increasing prevalence of childhood obesity has been met with increased presence and earlier onset of CVD risk factors [1-3]. Approximately $30 \%$ of overweight/obese children display an adverse lipid profile characterized by elevated total cholesterol (TC), low density lipoprotein cholesterol (LDL-C), and triglyceride (TG) and lowhigh-density lipoprotein cholesterol
(HDL-C) [4], altogether increasing risk for the development of cardiovascular diseases (CVD) [3]. The well-established clustering of obesity, CVD, and dyslipidemia in adults has guided efforts towards reductions in adiposity to lower risk of adverse events $[\mathbf{5}, \mathbf{6}]$. However, the decline in cardiometabolic health is initiated in childhood and is accelerated by the presence and duration of known risk factors, including obesity and dyslipi- 
Patel et al. Journal of Diabetes Research \& Clinical Metabolism 2015,

demia necessitating early intervention [7].

Both the American Heart Association and the American College of Sports Medicine have endorsed resistance training as integral for promoting health and preventing cardiovascular disease $[\mathbf{8 , 9}$. Engaging in efforts which capitalize on musculoskeletal health may be a unique approach for optimizing lipid profile. Studies in adults have established the potential role for resistance training in improving lipid profile [10-12]. Approximately $90 \%$ of energy utilized by skeletal muscle in the rested state is derived from lipid oxidation [13]. Given the elevated free fatty acid uptake by skeletal muscle during muscle contraction [14], resistance training is likely to play a role in lipidemia. Beyond the capacity for gain in muscle fiber size and strength, resistance training improves lipid metabolism by lowering the synthesis of free fatty acids and stimulating lipid oxidation [15]. In a cohort of young men decreases in total and LDL-C, independent of loss in fat mass, after participation in a 10 -week resistance training program has been reported [10]. The extent, however, to which skeletal muscle activation through resistance training during growth and development influences lipid profile to our knowledge has not been adequately studied.

The objective of this pilot study was to evaluate the effect of an 8-week resistance training intervention on lipid profile in obese early pubertal boys ages $10-12$ years. Due to the anabolic effects of insulin on musculoskeletal development [16], we also evaluated the contribution of circulating insulin concentration on lipid profile.

\section{Methods}

\section{Subjects}

Participants included 8 overweight/obese African American boys aged 10-12 years enrolled in a 24-week intervention study (NCT02040727). Data describing protocol and methods for these studies have been published [17]. All participants were pre- or early pubertal (Tanner stage $<3$ ) according to the criteria of Marshall and Tanner [18]. The study physician conducted an overall health assessment for each of the participants to rule out medical diagnoses. Exclusion criteria included medical diagnosis (e.g., diabetes; impaired fasting glucose, hypertension) or current use of medications that could affect the ability to perform resistance exercise, body composition, and lipid or glucose metabolism (e.g., use of thyroid medication, beta-blockers, or insulin sensitizers). In addition, participation or intention to participate in strenuous exercise concurrent with the study was an exclusionary criterion. Prior to being enrolled in the study, the purpose, protocol, and risk were explained to the subjects and their guardian(s) in detail. Following, subjects and their guardian(s) provided informed assent and consent, respectively. The research protocol was approved by the Institutional Review Board for human subjects at the University of Alabama at Birmingham (UAB). All measurements were performed at the Clinical Research Unit (CRU) and the Department of Nutrition
Sciences at UAB between October 2013 and January 2014.

\section{Experimental design}

The participants were randomly assigned into one of two groups: observational control $(n=3)$ or resistance training group $(n=5)$. Data were obtained at baseline and at 8 weeks for this investigation. Prior to participation in the resistance training intervention, those randomized to that groupwere familiarized with the exercise equipment as well as the proper techniques for the proposed exercise protocol. Preand post (8-week) assessments of strength, anthropometry, body composition, and a fasting blood draw were completed. The resistance training began within one week of baseline assessments with training exercise three days per week for 8 weeks (described in detail below).

\section{Anthropometrics}

Height (to the nearest 0.1 inches) and weight (to the nearest $0.1 \mathrm{~kg}$ ) were measured in minimal clothing and without shoes using a digital stadiometer (Heightronic 235; Measurement Concepts, Snoqualmi, WA, USA) and scale (Scale-Tronix 6702W; Scale-Tronix, Carol Stream IL, USA). BMI was calculated as the weight in kilograms divided by the height in meters squared. BMI percentile, overweight (BMI $\geq 85^{\text {th }}$ percentile), and obesity status (BMI $\geq 95^{\text {th }}$ percentile) were defined using sex- and age-specific CDC growth charts.

\section{Pubertal status}

Pubertal status was determined using Tanner staging by direct observation according to the guidelines of Marshall and Tanner [18]. A composite number was assigned representing the higher of the two values defined by both testicular volume and pubic hair.

\section{Assessment of body composition}

Body composition, including total body fat mass, percent body fat, lean mass, and bone mineral density (BMD), was measured at baseline by dual-energy $x$-ray absorptiometry (DXA) using a GE Lunar Prodigy densitometer (GE LUNAR Radiation Corp., Madison, WI). Participants were scanned in light clothing, while lying flat on their backs. Scans were analyzed using pediatric software (encore 2002 Version 6.10.029).

\section{Serum analysis}

Blood samples were obtained through venipuncture in the morning after an overnight fast. Triglycerides (TG) were measured with the glyceryl phosphate method. HDL was analyzed using a two-reagent system involving stabilization of LDL-C, very low-density lipoprotein cholesterol (VLDL), and chylomicrons using cyclodextrin and dextrin sulfate, and subsequent enzymatic-colorimetric detection of HDL-C. LDL$C$ was calculated using the Friedewald equation. Insulin was analyzed using a TOSOH AIA-600 II Automated Immunoassay Analyzer (TOSOH Bioscience, South San Francisco, CA, USA). 
Minimum assay sensitivity was $0.5 \mathrm{uU} / \mathrm{ml}$, mean intra-assay CV was $4.69 \%$, and inter-assay CV was $6.0 \%$. Glucose was measured in $12 \mu \mathrm{L}$ sera with the glucose oxidase method using a SIRRUS analyzer (interassay CV 2.56\%). Homeostatic model assessment approximating insulin resistance (HOMAIR) was calculated by dividing the product of glucose and insulin concentration by 405 .

\section{Strength testing}

All subjects underwent strength testing following the same procedures at baseline and 8-weeks. Aone-repetition maximum (1-RM) strength test was performed for both the bench press and squat. Before the 1-RM strength test, subjects were instructed to warm-up for fiveminutes on either a treadmill or cycle ergometer. The 1-RM measurements were assessed while gradually increasing the resistance after each successful attempt until failure was reached. Success was determined by a trainer based on the completion of a full repetition with proper form and full range of motion. Between each attempt, a one minute rest period was given.

\section{Resistance training program}

Participants underwent supervised resistance training for 8 weeks on three nonconsecutive days per week. Each training session began with a five minute warm-up period which was conducted on either the treadmill or cycle ergometer. The resistance training program was designed to stimulate all major muscle groups through seven exercises: alternating bench press (twice per week) and pushups (once a week), squats, pull downs or rows, alternating jump squats (twice per week) and lunges (once per week), overhead press, heel raises, and abdominal crunches. Each exercise consisted of 10-15 repetitions to fatigue for a total of three sets per exercise. Furthermore, exercises stimulating upper and lower body muscle groups were paired into a superset and a one-minute rest period was given between each superset.

\section{Statistical analysis}

Data analysis was conducted using SPSS (version 22). All data values were expressed as means \pm standard deviation. Differences at baseline between the two groups were examined using independent samples t-tests. Pearson's simple correlations were first used to assess the relationships between lipid, insulin and strength parameters. To evaluate pre-to-post differences within group, paired t-test were performed. Differences between groups were evaluated by ANCOVA including individual lipid parameters concentration and insulin at baselineand Tanner stage. Additional models were evaluated controlling for independent contributions of insulin or body composition (lean or fat mass). Statistical significant was set as $\mathrm{P}<0.05$.

\section{Results}

Baseline descriptive characteristics, including demographics, body composition, 1-RM strength measures, and serum measurements in both groups are presented in Table 1. There were no differences between groups in any of the variables.

Eight-week characteristics are presented in Table 2. Time effect analysis revealed a significant increase in height of both groups and weight of the resistance trained group. Furthermore, the mean 1-RM squat significantly increased in the resistance trained group while the 1-RM bench press increased in the control group. No group effects were observed for any of the lipid parameters or insulin levels.

Figure 1 displays mean group differences in the serum lipid profile. An increase in TG among the resistance trained group and decrease in TG in the control group led to an observed group difference $(p=0.02)$. We next investigated the correlation between serum insulin levels and lipid profile (Table 3). In the entire cohort, there were no significant correlations between insulin or lipid profile at baseline or at 8-weeks. When evaluated by group, no correlations were observed in the control group at baseline or follow-up. However, among resistance

Table 1. Baseline descriptive characteristics (mean \pm SD) of resistance trained $(n=5)$ and control group $(n=3)$.

\begin{tabular}{|c|c|c|}
\hline Variable & $\begin{array}{l}\text { Resistance trained } \\
\text { group }\end{array}$ & Control group \\
\hline Age (years) & $11.2 \pm 1.1$ & $11.0 \pm 1.0$ \\
\hline Tanner stage & $1.2 \pm 0.5$ & $1.3 \pm 0.6$ \\
\hline Height $(\mathrm{cm})$ & $151.58 \pm 4.71$ & $165.51 \pm 12.98$ \\
\hline Weight (kg) & $67.2 \pm 19.0$ & $74.1 \pm 10.0$ \\
\hline BMI $\left(\mathrm{kg} / \mathrm{m}^{2}\right)$ & $29.1 \pm 7.6$ & $27.4 \pm 5.7$ \\
\hline BMI \% & $98^{\text {th }}$ & $98^{\text {th }}$ \\
\hline \multicolumn{3}{|c|}{ Body composition measurements } \\
\hline Total fat mass (kg) & $26.1 \pm 15.1$ & $26.6 \pm 10.1$ \\
\hline Percentage body Fat (\%) & $38.6 \pm 11.4$ & $36.6 \pm 11.6$ \\
\hline Lean mass (kg) & $37.6 \pm 6.5$ & $44.9 \pm 6.2$ \\
\hline $\mathrm{BMC}(\mathrm{kg})$ & $1.8 \pm 0.3$ & $2.3 \pm 0.4$ \\
\hline $\mathrm{BMD}\left(\mathrm{g} / \mathrm{cm}^{2}\right)$ & $1.037 \pm 0.098$ & $1.047 \pm 0.068$ \\
\hline \multicolumn{3}{|c|}{ Muscle strength measurements } \\
\hline 1-RM bench press (lb) & $112.0 \pm 32.5$ & $110.0 \pm 31.2$ \\
\hline 1-RM squat (lb) & $150.0 \pm 53.5$ & $145.0 \pm 52.0$ \\
\hline \multicolumn{3}{|l|}{ Serum measurements } \\
\hline $\mathrm{TC}(\mathrm{mg} / \mathrm{dl})$ & $141.8 \pm 23.0$ & $163.0 \pm 68.6$ \\
\hline LDL-C (mg/dl) & $76.6 \pm 25.2$ & $90.3 \pm 60.4$ \\
\hline HDL-C (mg/dl) & $55.6 \pm 9.8$ & $55.7 \pm 3.1$ \\
\hline $\mathrm{TG}(\mathrm{mg} / \mathrm{dl})$ & $48.2 \pm 21.7$ & $85.3 \pm 37.9$ \\
\hline Insulin $(\mu \mathrm{U} / \mathrm{ml})$ & $10.1 \pm 6.1$ & $13.0 \pm 5.4$ \\
\hline Glucose (mg/dl) & $90.6 \pm 5.2$ & $91.0 \pm 7.8$ \\
\hline HOMA-IR & $2.27 \pm 1.36$ & $2.88 \pm 1.06$ \\
\hline
\end{tabular}

RT: Resistance trained; TC: Total cholesterol; TG: Triglycerides; HDL-C: High density lipoprotein cholesterol; LDL-C: Low density lipoprotein cholesterol 
Patel et al. Journal of Diabetes Research \& Clinical Metabolism 2015,

http://www.hoajonline.com/journals/pdf/2050-0866-4-2.pdf

Table 2. Anthropometric, muscle strength measures, and serum measures after 8 weeks of training.

\begin{tabular}{|c|c|c|c|c|c|}
\hline Variable & Group & 8 weeks & Difference & Time effect & Group effect \\
\hline \multirow{2}{*}{ Height $(\mathrm{cm})$} & RT & $153.60 \pm 4.86$ & $2.02 \pm 0.68$ & 0.003 & \multirow{2}{*}{0.5} \\
\hline & Control & $167.08 \pm 12.84$ & $1.57 \pm 0.15$ & 0.003 & \\
\hline \multirow{2}{*}{ Weight (kg) } & RT & $69.8 \pm 20.6$ & $2.6 \pm 2.0$ & 0.04 & \multirow{2}{*}{0.6} \\
\hline & Control & $77.8 \pm 8.8$ & $3.8 \pm 2.3$ & 0.1 & \\
\hline \multirow{2}{*}{ BMI $\left(\mathrm{kg} / \mathrm{m}^{2}\right)$} & $\mathrm{RT}$ & $29.4 \pm 8.0$ & $0.3 \pm 0.6$ & 0.3 & \multirow{2}{*}{0.3} \\
\hline & Control & $28.3 \pm 6.0$ & $0.9 \pm 1.0$ & 0.3 & \\
\hline \multicolumn{6}{|c|}{ Muscle strength measurements } \\
\hline \multirow{2}{*}{ 1-RM Bench (lb) } & $\mathrm{RT}$ & $146.0 \pm 49.4$ & $34.0 \pm 36.8$ & 0.1 & \multirow{2}{*}{0.8} \\
\hline & Control & $136.7 \pm 25.7$ & $26.7 \pm 5.8$ & 0.02 & \\
\hline \multirow{2}{*}{ 1-RM Squat (lb) } & RT & $236.0 \pm 72.1$ & $86.0 \pm 35.4$ & 0.006 & \multirow{2}{*}{0.3} \\
\hline & Control & $185.0 \pm 37.7$ & $40.0 \pm 87.9$ & 0.5 & \\
\hline \multicolumn{6}{|c|}{ Serum measurements } \\
\hline \multirow{2}{*}{$\mathrm{TC}(\mathrm{mg} / \mathrm{dl})$} & RT & $131.4 \pm 16.9$ & $-10.4 \pm 11.7$ & 0.1 & \multirow{2}{*}{0.3} \\
\hline & Control & $150.0 \pm 43.4$ & $-13.0 \pm 33.0$ & 0.6 & \\
\hline \multirow{2}{*}{ LDL-C (mg/dl) } & RT & $66.0 \pm 16.0$ & $-10.5 \pm 10.1$ & 0.08 & \multirow{2}{*}{0.3} \\
\hline & Control & $75.4 \pm 43.8$ & $-14.9 \pm 18.5$ & 0.3 & \\
\hline \multirow{2}{*}{$\mathrm{HDL}-\mathrm{C}(\mathrm{mg} / \mathrm{dl})$} & RT & $53.0 \pm 11.3$ & $-2.6 \pm 3.0$ & 0.1 & \multirow{2}{*}{0.3} \\
\hline & Control & $61.3 \pm 10.4$ & $5.7 \pm 12.4$ & 0.5 & \\
\hline \multirow{2}{*}{$\mathrm{TG}(\mathrm{mg} / \mathrm{dl})$} & RT & $61.8 \pm 24.8$ & $13.6 \pm 12.6$ & 0.07 & \multirow{2}{*}{0.2} \\
\hline & Control & $66.3 \pm 41.6$ & $-19.0 \pm 17.8$ & 0.2 & \\
\hline \multirow{2}{*}{ Insulin $(\mu \mathrm{U} / \mathrm{ml})$} & RT & $12.9 \pm 9.0$ & $2.8 \pm 3.5$ & 0.1 & \multirow{2}{*}{0.6} \\
\hline & Control & $12.0 \pm 2.5$ & $-1.0 \pm 2.9$ & 0.6 & \\
\hline \multirow{2}{*}{ Glucose (mg/dl) } & RT & $94.8 \pm 7.8$ & $4.2 \pm 4.1$ & 0.08 & \multirow{2}{*}{0.3} \\
\hline & Control & $92.3 \pm 8.3$ & $1.3 \pm 5.9$ & 0.7 & \\
\hline \multirow{2}{*}{ HOMA-IR } & RT & $3.08 \pm 2.18$ & $0.81 \pm 0.95$ & 0.1 & \multirow{2}{*}{0.8} \\
\hline & Control & $2.69 \pm 0.31$ & $-0.19 \pm 0.77$ & 0.7 & \\
\hline
\end{tabular}

Significant difference between pre- and post-values were assessed through paired $t$-test $(p<0.05)$. Group differences were controlled for baseline measures, Tanner stage, and lean mass. Significant differences between groups was defined as $\mathrm{p}<0.05$.

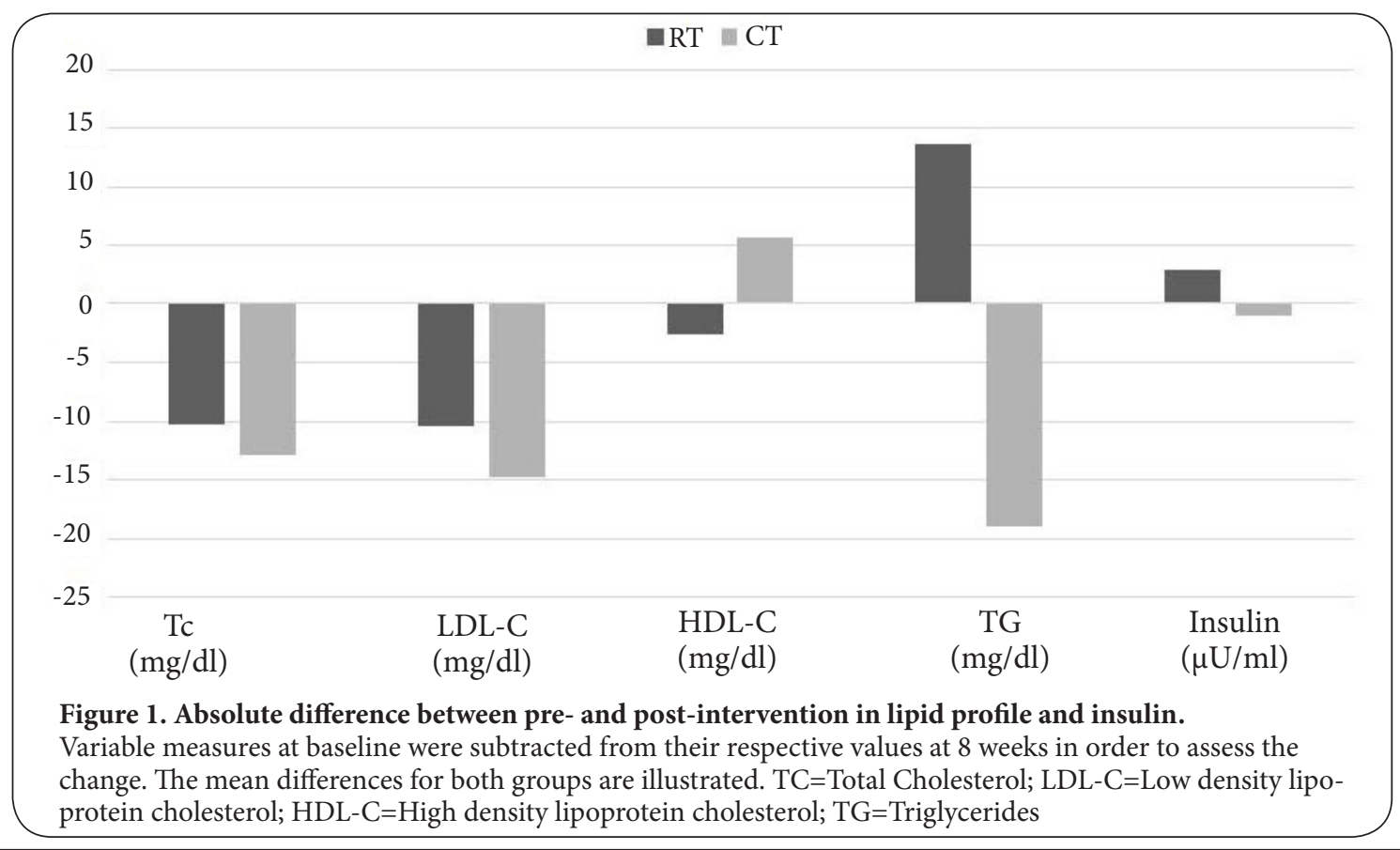


Table 3. Association between insulin level and lipid parameters at baseline and post- 8 weeks in the resistance trained group and total sample.

\begin{tabular}{|c|c|c|}
\hline \multicolumn{3}{|c|}{ A. Total sample. } \\
\hline \multirow[t]{2}{*}{ Variables } & Baseline & After 8 weeks \\
\hline & $\mathbf{r}$ & $\mathbf{r}$ \\
\hline TC & 0.403 & 0.263 \\
\hline HDL-C & -0.336 & -0.183 \\
\hline LDL-C & 0.423 & 0.269 \\
\hline TG & 0.520 & 0.378 \\
\hline \multicolumn{3}{|c|}{ B. Control group } \\
\hline \multirow[t]{2}{*}{ Variables } & Baseline & After 8 weeks \\
\hline & $\mathbf{r}$ & $\mathbf{r}$ \\
\hline TC & 0.068 & -0.508 \\
\hline HDL-C & 0.980 & -0.201 \\
\hline LDL-C & 0.038 & -0.328 \\
\hline TG & -0.084 & -0.670 \\
\hline \multicolumn{3}{|c|}{ C. Resistance trained group } \\
\hline \multirow[t]{2}{*}{ Variables } & Baseline & After 8 weeks \\
\hline & $\mathbf{r}$ & $\mathbf{r}$ \\
\hline TC & $0.897^{\star}$ & $0.831^{\wedge}$ \\
\hline HDL-C & -0.555 & -0.179 \\
\hline LDL-C & $0.876^{\wedge}$ & 0.765 \\
\hline TG & $0.940^{*}$ & 0.770 \\
\hline
\end{tabular}

*Significant correlation between insulin and lipid variable $(\mathrm{p}<0.05) . \wedge$ Marginal correlation between insulin and lipid variable $(\mathrm{p}<0.1)$. TC=Total Cholesterol; LDL-C=Low density lipoprotein cholesterol; HDL-C=High density lipoprotein cholesterol; TG=Triglycerides

trained boys, a positive correlation was observed between insulin and bothTC $(r=0.897, p=0.04)$ and TG $(r=0.940, p=0.02)$ at baseline. In addition, there was a marginally significant relationship between insulin and LDL-C $(r=0.876, p=0.05)$. After 8 weeks, the relationship between these variables was not apparent ( $p=0.08,0.1$, and 0.1 respectively).

Due to wide variations in insulin particularly salient during early maturation, the relationship was further clarified by investigation the correlation between HOMA-IR and lipid profile in Table 4. In the total sample, there were no significant correlations between HOMA-IR or lipid profile at baseline or at 8-weeks. Group analysis showed a significant correlation between HOMA-IR and HDL-C in the control group ( $r=1.000$, $p=0.02$ ). Baseline measures in the resistance trained group showed a positive correlation between HOMA-IR and TG $(r=0.915, p=0.03)$. In addition, there was a marginally significant relationship between HOMA-IR and both TC $(r=0.872, p=0.05)$ and LDL-C $(r=0.870, p=0.06)$. After 8 weeks, the relationship between these variables in both groups was attenuated $(p=0.8,0.2,0.1$ and 0.1 respectively).
Table 4. Association between HOMA-IR and lipid parameters at baseline and post- 8 weeks in the resistance trained group and total sample.

\begin{tabular}{|c|c|c|}
\hline \multicolumn{3}{|c|}{ A. Total sample. } \\
\hline \multirow{2}{*}{ Variables } & Baseline & After 8 weeks \\
\hline & $\mathbf{r}$ & $\mathbf{r}$ \\
\hline TC & 0.471 & 0.278 \\
\hline HDL-C & -0.384 & -0.220 \\
\hline LDL-C & 0.499 & 0.295 \\
\hline TG & 0.573 & 0.402 \\
\hline \multicolumn{3}{|c|}{ B. Resistance trained group } \\
\hline \multirow{2}{*}{ Variables } & Baseline & After 8 weeks \\
\hline & $\mathbf{r}$ & $\mathbf{r}$ \\
\hline TC & $0.872^{\wedge}$ & 0.789 \\
\hline HDL-C & -0.588 & -0.207 \\
\hline LDL-C & $0.870^{\wedge}$ & 0.756 \\
\hline TG & $0.915^{*}$ & 0.721 \\
\hline \multicolumn{3}{|c|}{ C. Control group } \\
\hline \multirow[t]{2}{*}{ Variables } & Baseline & After 8 weeks \\
\hline & $\mathbf{r}$ & $\mathbf{r}$ \\
\hline TC & 0.240 & -0.428 \\
\hline HDL-C & $1.000^{*}$ & -0.290 \\
\hline LDL-C & 0.211 & -0.241 \\
\hline TG & 0.090 & -0.600 \\
\hline
\end{tabular}

*Significant correlation between insulin and lipid variable $(\mathrm{p}<0.05) . \wedge$ Marginal correlation between insulin and lipid variable $(\mathrm{p}<0.1)$. TC $=$ Total Cholesterol; $\mathrm{LDL}-\mathrm{C}=\mathrm{Low}$ density lipoprotein cholesterol; HDL-C $=$ High density lipoprotein cholesterol; $\mathrm{TG}=$ Triglycerides

\section{Discussion}

Resistance training is associated with changes in enzyme, hormone and metabolite concentrations that may influence growth and development during puberty. For obese boys, in particular increases in lean mass can influence fuel utilization. In the current study, participating in 8-weeks of resistance trainingresulted insignificant gains in strength which coincided an increase in weight. It is plausible that the increase in weight only in the intervention group (concordant with an increase in height in both group), represented an increase in lean mass. Our findings provide preliminary evidence that resistance training may also decrease $L D L-C$, although this remains to be confirmed in a larger cohort. Further, the resistance trained group exhibited a non-statistically significant increase in TG. However, mean TG remained within normal limits. No changes in lipid profile were detected in control group after eight weeks. A meta-analysis has reported a decrease in TG with resistance training, but also noted a decrease in body fat which may contribute to the inconsistent findings [19]. The increased TG could result from a greater need for 
Patel et al. Journal of Diabetes Research \& Clinical Metabolism 2015,

fuel delivery, including a greater reliance on oxidative fuels, such as fat, during resistance training, although this requires confirmation.

Our findings are discordant to some but not all similar studies in adults and in children. In overweight/obese adults (ages 18-35), Jimenez et al., observed a reduction in LDL-C (-11.4 $\mathrm{mg} / \mathrm{dL}, \mathrm{p}=0.03)$ and an increase in $\mathrm{HDL}-\mathrm{C}(3.2 \mathrm{mg} / \mathrm{dL}, \mathrm{p}=0.04)$ after a 8-week resistance training regimen [20]. Impact on LPL and hepatic triglyceride lipase in the mechanism described by Despres and Lamarche in endurance exercise may also play a role in the strength training [21]. In the sedentary state, the low LPL and high HTGL activities lead to a decrease in the production of HDL particles as a result of reduced catabolism of triglyceride rich lipoproteins, which in turn also reduces HDL. However, in physically active individuals, the LPL activity is high, which contributes to the generation of HDL particles. During growth and development a differential effect related to sexual maturation between may explain the difference in findings between that of Jiminez et al., and the current investigation as puberty is associated with changes in growth hormone, insulin-like growth factor-1, and testosterone, all known to influence energy metabolism [22]. Contrary to our results in the pediatric population, a study conducted by Sung et al., on 82 obese children (ages 8-11) showed significant decreases in total cholesterol and LDL-C after resistance training for 6-weeks [23]. Our findings are in agreement with previous reports presented byboth Lau et al., and Watts et al., studied the effects of resistance training on lipid profile in obese adolescents (ages 10-17 and 14.3 1 1.5, respectively) and reported no significant changes in concentrations of

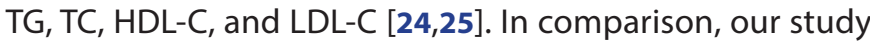
differed in terms of the training protocol as Lau et al., which incorporated 10 exercises conducted for 5 repetitions and Watts et al., which incorporated aerobic exercise into their strength training program. These differences may variably affect lipid profile due to differences in fuel utilization with different exercise modalities [26,27].

In adults, resistance training has been shown to restore lipid homeostasis in obese individuals through altered mobilization and delivery to muscle [28]. Increases inskeletal muscle lipoprotein lipase (LPL) expression [29], which are suggested to be mediated through exercise-induced production of AMP-activated protein kinase (AMPK) [30], allow muscle to clear greater quantities of circulating lipids. AMPK is also observed to be activated in both the liver and adipose tissue where it is associated with decreases in a number of enzymes involved in lipid synthesis [31]. Further, exercise is observed to improve the reverse cholesterol transport by facilitating $\mathrm{HDL}-\mathrm{C}$ function and increasing liver expression of LDL receptor, increasing hepatic uptake of LDL-C from circulation [32] and decreasing HTGL. Even though resistance training has strong potential to clear circulating cholesterol, the current investigation did not report quantitative change in lipid profile in the pediatric overweight/obese population. One may speculate that in order to observe detectable changes in absolute lipid levels, a longer duration of the study may be needed. Alternatively, considering recent investigations into the various subclasses of LDL-C, it could be proposed that resistance training may instigate qualitative changes in lipid profile rather than quantitative. Recent investigations have suggested that BMI is positively associated with the small-dense LDL-C: large-buoyant LDL-C ratio [33], facilitating the atherosclerotic process in obese individuals [34]. However, physical activity has been linked to a shift towards the production of large particle LDL-C [33], associated with a relative decrease CVD risk in comparison to small-particle. Although lipoprotein subclasses were not assessed in the current investigation, future studies incorporating qualitative lipoprotein analysis may provide a more comprehensive perspective into the effects of resistance training on lipid profile. The extent to which developmental stage is associated with the effects of resistance training on lipid profile and the manner in which lipids may be differentially regulated and utilized in African Americans during puberty warrant further investigation.

At baseline in the resistance trained group, we observed that insulin was positively correlated with TG $(p=0.02)$ and TC $(p=0.04)$, and there was a marginal, positive correlation with LDL-C $(p=0.05)$. Similarly, at baseline in the resistance trained group, a positive correlation between HOMA-IR and TG $(p=0.03)$ was observed, along with a marginal, positive correlation with TC $(p=0.05)$ and LDL-C (0.06). After 8-weeks, relationships with both insulin and HOMA-IR diminished which may be related to the limited sample size. Alternatively, the absence of association of HDL-C with either insulin or HOMA-IR in the resistance trained group may be related to the African American genetic predisposition to increased LPL activity in the liver, leading to better HDL-C independent of insulin dynamics [35].

Strengths of this study include robust assessment of body composition measured through DXA to allow for detection of independent associations. However, this study was limited in the small sample size and inclusion of only overweight/obese, pre-/early pubertal African American Boys, therefore limiting the generalizability of the findings. Age- and Tanner-stage matched controls across body habitus would enhance our ability to determine a potential growth and obesity related interaction of resistance training and lipid mobilization. Further, the long-term effects of resistance training on lipid profile are not fully elucidated. Due to the potential confounding effects of dietary differences, further investigations would also benefit by controlling for diet.

\section{Conclusion}

Improvements in lipid profile were not detected, whereas an increase in TG was observed among resistance-trained subjects. These findings may be a result of increase lipid mobilization to fuel growth-related process during puberty. Further investigations with a larger, diverse sample size are 
necessary to explore the role of lipids in human physiology during adolescence and to clarify longer term the effects of resistance training on lipid profile in obese and non-obese youth.

\section{Competing interests}

The authors declare that they have no competing interests.

Authors' contributions

\begin{tabular}{|l|c|c|c|c|c|c|}
\hline Authors' contributions & SJP & LJH & APA & OMG & MMB & KC \\
\hline Research concept and design & -- & $\checkmark$ & -- & -- & -- & $\checkmark$ \\
\hline Collection and/or assembly of data & $\checkmark$ & $\checkmark$ & -- & -- & -- & $\checkmark$ \\
\hline Data analysis and interpretation & -- & $\checkmark$ & $\checkmark$ & $\checkmark$ & $\checkmark$ & $\checkmark$ \\
\hline Writing the article & $\checkmark$ & $\checkmark$ & $\checkmark$ & $\checkmark$ & $\checkmark$ & $\checkmark$ \\
\hline Design of figures & -- & $\checkmark$ & -- & -- & -- & $\checkmark$ \\
\hline Critical revision of the article & $\checkmark$ & $\checkmark$ & $\checkmark$ & $\checkmark$ & $\checkmark$ & $\checkmark$ \\
\hline Final approval of article & $\checkmark$ & $\checkmark$ & $\checkmark$ & $\checkmark$ & $\checkmark$ & $\checkmark$ \\
\hline Statistical analysis & $\checkmark$ & $\checkmark$ & -- & -- & -- & $\checkmark$ \\
\hline
\end{tabular}

Acknowledgement

We would like to thank the staff of UAB's Center for

Exercise Science and Clinical Research Unit for their aid

in the study and to all subjects for their participation.

Publication history

Editors: Sasanka Ramanadham, University of Alabama School of Medicine, USA.

Toshiyasu Sasaoka, University of Toyama, Japan.

EIC: Geoffrey Burnstock, University College London, UK.

Received: 06-Dec-2014 Final Revised: 23-Jan-2015

Accepted: 10-Feb-2015 Published: 16-Feb-2015

\section{References}

1. Steinberger J, Moorehead C, Katch V and Rocchini AP. Relationship between insulin resistance and abnormal lipid profile in obese adolescents. J Pediatr. 1995; 126:690-5. | Article | PubMed

2. Bridger T. Childhood obesity and cardiovascular disease. Paediatr Child Health. 2009; 14:177-82. | PubMed Abstract | PubMed Full Text

3. Steinberger J and Daniels SR. Obesity, insulin resistance, diabetes, and cardiovascular risk in children: an American Heart Association scientific statement from the Atherosclerosis, Hypertension, and Obesity in the Young Committee (Council on Cardiovascular Disease in the Young) and the Diabetes Committee (Council on Nutrition, Physical Activity, and Metabolism). Circulation. 2003; 107:1448-53. | Article | PubMed

4. Caprio S, Hyman LD, McCarthy S, Lange R, Bronson M and Tamborlane WV. Fat distribution and cardiovascular risk factors in obese adolescent girls: importance of the intraabdominal fat depot. Am J Clin Nutr. 1996; 64:12-7. | Article | PubMed

5. Mosca L, Rubenfire M, Tarshis T, Tsai A and Pearson T. Clinical predictors of oxidized low-density lipoprotein in patients with coronary artery disease. Am J Cardiol. 1997; 80:825-30. | Article | PubMed

6. Lamb MM, Ogden CL, Carroll MD, Lacher DA and Flegal KM. Association of body fat percentage with lipid concentrations in children and adolescents: United States, 1999-2004. Am J Clin Nutr. 2011; 94:877-83. | Article | PubMed

7. McGill HC, Jr., McMahan CA, Herderick EE, Zieske AW, Malcom GT, Tracy $\mathrm{RE}$ and Strong JP. Obesity accelerates the progression of coronary atherosclerosis in young men. Circulation. 2002; 105:2712-8. | Article | PubMed

8. Williams MA, Haskell WL, Ades PA, Amsterdam EA, Bittner V, Franklin BA, Gulanick M, Laing ST and Stewart KJ. Resistance exercise in individuals with and without cardiovascular disease: 2007 update: a scientific statement from the American Heart Association Council on Clinical Cardiology and Council on Nutrition, Physical Activity, and Metabolism. Circulation. 2007; 116:572-84. | Article | PubMed

9. Braith RW and Stewart KJ. Resistance exercise training: its role in the prevention of cardiovascular disease. Circulation. 2006; 113:2642-50. Article I PubMed

10. Perez-Gomez J, Vicente-Rodriguez G, Ara Royo I, Martinez-Redondo D, Puzo Foncillas J, Moreno LA, Diez-Sanchez C and Casajus JA. Effect of endurance and resistance training on regional fat mass and lipid profile. Nutr Hosp. 2013; 28:340-6. I Pdf I PubMed

11. Sheikholeslami Vatani D, Ahmadi S, Ahmadi Dehrashid K and Gharibi F. Changes in cardiovascular risk factors and inflammatory markers of young, healthy, men after six weeks of moderate or high intensity resistance training. J Sports Med Phys Fitness. 2011; 51:695-700. | Article I PubMed

12. Kokkinos PF and Hurley BF. Strength training and lipoprotein-lipid profiles. A critical analysis and recommendations for further study. Sports Med. 1990; 9:266-72. I Article I PubMed

13. Consitt LA, Bell JA and Houmard JA. Intramuscular lipid metabolism, insulin action, and obesity. IUBMB Life. 2009; 61:47-55. | Article | PubMed Abstract | PubMed Full Text

14. Kiens B. Skeletal muscle lipid metabolism in exercise and insulin resistance. Physiol Rev. 2006; 86:205-43. I Article I PubMed

15. Bosma M. Lipid homeostasis in exercise. Drug Discov Today. 2014; 19:1019-23. | Article | PubMed

16. Chow LS, Albright RC, Bigelow ML, Toffolo G, Cobelli C and Nair KS Mechanism of insulin's anabolic effect on muscle: measurements of muscle protein synthesis and breakdown using aminoacyl-tRNA and other surrogate measures. Am J Physiol Endocrinol Metab. 2006; 291:E729-36. | Article | PubMed

17. Hanks LJ, Casazza K, Ashraf AP, Wallace S and Gutierrez OM. Fibroblast growth factor-21, body composition, and insulin resistance in prepubertal and early pubertal males and females. Clin Endocrinol (Oxf). 2014. | Article | PubMed

18. Marshall WA and Tanner JM. Growth and physiological development during adolescence. Annu Rev Med. 1968; 19:283-300. | Article | PubMed

19. Cornelissen VA, Fagard RH, Coeckelberghs E and Vanhees L. Impact of resistance training on blood pressure and other cardiovascular risk factors: a meta-analysis of randomized, controlled trials. Hypertension. 2011; 58:950-8. | Article

20. Hernan Jimenez $O$ and Ramirez-Velez R. [Strength training improves insulin sensitivity and plasma lipid levels without altering body composition in overweight and obese subjects]. Endocrinol Nutr. 2011; 58:169-74. | Article | PubMed

21. Couillard C, Despres JP, Lamarche B, Bergeron J, Gagnon J, Leon AS, Rao DC, Skinner JS, Wilmore JH and Bouchard C. Effects of endurance exercise training on plasma HDL cholesterol levels depend on levels of triglycerides: evidence from men of the Health, Risk Factors, Exercise Training and Genetics (HERITAGE) Family Study. Arterioscler Thromb Vasc Biol. 2001; 21:1226-32. | Article | PubMed

22. Riddell MC. The endocrine response and substrate utilization during exercise in children and adolescents. J Appl Physiol (1985). 2008; 105:725-33. | Article | PubMed

23. Sung RY, Yu CW, Chang SK, Mo SW, Woo KS and Lam CW. Effects of dietary intervention and strength training on blood lipid level in obese children. Arch Dis Child. 2002; 86:407-10. | Article | PubMed Abstract | PubMed Full Text

24. Lau P.W.C. et al. The physiological and pschological effects of resistance training on chinese obese adolescents. Journal of Exercise Science \& Fitness. 2004; 2:115-120. | Pdf

25. Watts K, Beye P, Siafarikas A, Davis EA, Jones TW, O'Driscoll G and Green DJ. Exercise training normalizes vascular dysfunction and improves central adiposity in obese adolescents. J Am Coll Cardiol. 2004; 43:18237. | Article | PubMed 
Patel et al. Journal of Diabetes Research \& Clinical Metabolism 2015,

26. Lira FS, Yamashita AS, Uchida MC, Zanchi NE, Gualano B, Martins E, Jr., Caperuto EC and Seelaender M. Low and moderate, rather than high intensity strength exercise induces benefit regarding plasma lipid profile. Diabetol Metab Syndr. 2010; 2:31. | Article | PubMed Abstract | PubMed Full Text

27. Lira FS, Yamashita AS, Uchida MC, Zanchi NE, Gualano B, Martins E, Jr. Caperuto EC and Seelaender M. Low and moderate, rather than high intensity strength exercise induces benefit regarding plasma lipid profile. Diabetol Metab Syndr. 2010; 2:31. | Article | PubMed Abstract | PubMed Full Text

28. Boardley D, Fahlman M, Topp R, Morgan AL and McNevin N. The impact of exercise training on blood lipids in older adults. Am J Geriatr Cardiol. 2007; 16:30-5. | Article | PubMed

29. Seip RL, Mair K, Cole TG and Semenkovich CF. Induction of human skeletal muscle lipoprotein lipase gene expression by short-term exercise is transient. Am J Physiol. 1997; 272:E255-61. | Article | PubMed

30. Richter EA and Ruderman NB. AMPK and the biochemistry of exercise: implications for human health and disease. Biochem J. 2009; 418:26175. | Article | PubMed Abstract | PubMed Full Text

31. Park H, Kaushik VK, Constant S, Prentki M, Przybytkowski E, Ruderman NB and Saha AK. Coordinate regulation of malonyl-CoA decarboxylase, sn-glycerol-3-phosphate acyltransferase, and acetyl-CoA carboxylase by AMP-activated protein kinase in rat tissues in response to exercise. $J$ Biol Chem. 2002; 277:32571-7. I Article I PubMed

32. Rocco DD, Okuda LS, Pinto RS, Ferreira FD, Kubo SK, Nakandakare ER, Quintao EC, Catanozi S and Passarelli M. Aerobic exercise improves reverse cholesterol transport in cholesteryl ester transfer protein transgenic mice. Lipids. 2011; 46:617-25. | Article | PubMed

33. Parlesak A, Eckoldt J, Winkler K, Bode CJ and Schafer C. Intercorrelations of lipoprotein subfractions and their covariation with lifestyle factors in healthy men. J Clin Biochem Nutr. 2014; 54:174-80. I Article I PubMed Abstract | PubMed Full Text

34. Austin MA, Breslow JL, Hennekens CH, Buring JE, Willett WC and Krauss RM. Low-density lipoprotein subclass patterns and risk of myocardial infarction. JAMA. 1988; 260:1917-21. | Article | PubMed

35. Sumner AE. Ethnic differences in triglyceride levels and high-density lipoprotein lead to underdiagnosis of the metabolic syndrome in black children and adults. J Pediatr. 2009; 155:S7 e7-11. | Article | PubMed Abstract | PubMed Full Text

\section{Citation:}

Patel SJ, Hanks LJ, Ashraf AP, Gutierrez OM, Bamman MM and Casazza K. Effects of 8 week resistance training on lipid profile and insulin levels in overweight/obese peri-pubertal boys-a pilot study. J Diab Res Clin Met. 2015; 4:2. http://dx.doi.org/10.7243/2050-0866-4-2 